\title{
Simulative Analysis of Bidirectional BPON System at Low Insertion Losses and Attenuation
}

\author{
Maninderjeet Kaur \\ M. Tech. student, \\ Department of E.C.E, \\ Amritsar College of \\ Engineering and Technology, \\ Amritsar, India ${ }^{1}$
}

\author{
Atul Mahajan \\ Associate Professor, \\ Department of E.C.E, \\ Amritsar College of \\ Engineering and Technology, \\ Amritsar, India
}

\begin{abstract}
The impairments like insertion losses and attenuation at ODN (optical distribution network) are affected the performance of PON systems. In this paper, a BPON (broadband passive optical network) system is deployed to improve the performance of passive components at ODN which has a minimum insertion losses and attenuation is $0.1 \mathrm{~dB} / \mathrm{km}$ in optical fiber. The system performance is analyzed on the basis of parameters such as quality factor, minimum BER and eye height is demonstrated on simulator. It will enhance the network efficiency and capacity in optical communication system. Also, it will reduce the network termination cost and raise the number of users at receiver end by using 1:8splitter passive component.
\end{abstract}

Keywords

BPON, BER, Quality Factor and insertion losses

\section{INTRODUCTION}

With growing the rapid demand of multi-domain applications, users require a high capacity network. So PON technologies meet the requirement of huge bandwidth. Basically, PON is much suitable for FTTx (fiber to the $\mathrm{x}$ for home or buildings) implementation. It is also used to transmit a high speed broadband services i.e. audio, video and data both in upstream and downstream directions. In central offices, service supplier are present for connected the users to businesses and resident by using access network [1].For covering the large area, PON systems replaced point to point network with point to multipoint networks. The three main function units in which PON depends are central office(CO),remote node(RN),optical network unit(ONU).OLT(optical line terminal) is placed on $\mathrm{CO}$ which transfer the data from access node to ONU though a RN. The passive components are applied in RN, it does not needed a power [2].

In addition, primary PONs are deployed with three standards are BPON (ITU-T G.983), GPON (ITU-T G.984) and EPON (IEEE 802.3ah). These standards are employed with multiple access techniques are TDM, WDM, OFDM, OCDM and TWDM [3] for allowing huge bandwidth. Both BPON and GPON provide protection to avoiding a redundancy and resiliency. The WDM-PON commonly includes with greater transparency on protocols and bit rate [4]. Also, data packets are transmitted from OLT to each ONU with divergent wavelength in WDM-PON.

Recently, a BPON is deployed using a NRZ format and SMF offers low transmission losses and non linear impairments with splitting ratio 1:8 at ONU. For sustain a free operation between OLT and user site a passive component splitter is more suitable [5]. Crosstalk is also a factor degrading the quality of signal to noise ratio and quality factor [6]. A crosstalk affect is suppressed by using a WDM transmitter at OLT. In this paper, a BPON system is more tolerable from insertion losses and attenuation impairments. The most important goal in communication system to increase the transmission distance with low losses and attenuation. The performance of deployed system is analyzed in terms are quality factor, minimum BER and eye height using 7.0 optiSystem simulator.

\section{BIDIRECTIONAL BPON STRUCTURE}

Figure 1 shows the schematic architecture of bidirectional BPON in which data transmitted in both upstream and downstream directions. $\mathrm{L}$ band is required for downlink transmission and uplink used a $\mathrm{C}$ band because optical losses minimum in $\mathrm{C}$ band [7]. Multimedia services are provided to the clients in downstream and data is uploaded from clients in upstream direction. In BPON, a single WDM transmitter is placed at OLT is encapsulating with different components and different modulation formats for multiple channels is selected by a subscribers. WDM transmitter avoid the collision by providing dedicated wavelength is introduced during the transmission of the signals.

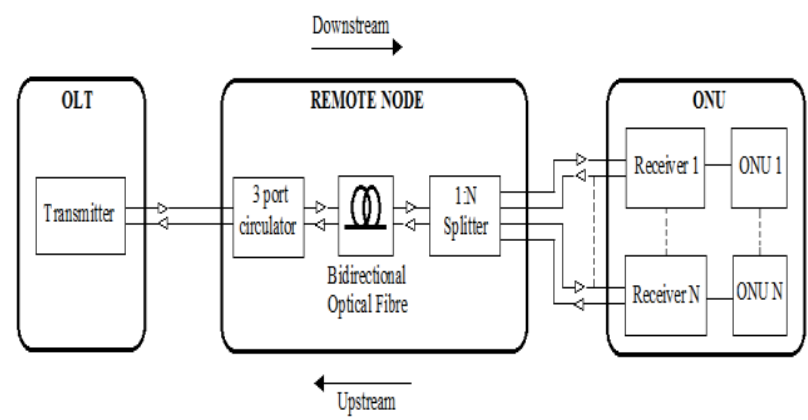

Fig.1 BPON Bidirectional architecture

The passive components circulator and splitter are present at ODN (optical distribution network) provide a straight connection between OLT and ONU. A $3 \mathrm{~dB}$ optical coupler i.e. splitter and circulator has a low loss budget [8] is used in network. The role of circulator are combined the multiple signals and give a single output. Further, single optical signal is transmitted to $1: 8$ splitter through bidirectional single mode fiber (SMF).Splitter divides the combine signal is coming from optical fiber [9] and it distribute into different ONUs. At ONU, signal is detected by receiver and performance of the system is analyzed by using a BER analyzer is produces a quality and bit error rate of the signals. 


\section{SIMULATION SETUP}

The simulation setup of bidirectional BPON system designed and analyzed by using 7.0optisystem software is shown in figure 2. For transmitting the voice/data in downstream direction $1490 \mathrm{~nm}$ wavelength channel is used, while $1550 \mathrm{~nm}$ wavelength channel is required for sending a video signal and $1300 \mathrm{~nm}$ wavelength is used to sending a data in upstream direction from ONU to OLT. In transmitter, internal pseudo random bit sequence (PRBS) generator is present on OLT to generate a NRZ modulation format and drive a laser diode (LD) is tuned at frequency $193.1 \mathrm{THz}$ and frequency spacing is $100 \mathrm{GHz}$. NRZ and RZ both modulation formats are used in BPON system but NRZ format is prefer due to sending a data over a large distance because NRZ is more tolerable from dispersion [10]. Also, a external modulator Mach-Zehnder Modulator (MZM) is used with extinction ratio is $15 \mathrm{~dB}$ in which optical signal is suppressed as a carrier and this signal is directly connected to a circulator. A circulator used as a MUX for combining the multiple signals and combined signal is launched into the bidirectional SMF having low transmission losses. The dispersion slope of SMF is $0.075 \mathrm{ps} / \mathrm{nm}^{\wedge} 2 / \mathrm{km}$ and dispersion is $16.75 \mathrm{ps} / \mathrm{nm} / \mathrm{km}$. As well as, a delay component is facilitating at $\mathrm{RN}$ to provide a delay between the optical signals by transmitting a null signal to productive port. The multiplexed signal from the optical fiber is fed to $1: 8$ splitter and split into 8 signals and distribute to 8 ONUs. At receiver, each ONU is connected to $3 \mathrm{R}$ regenerator. The main function of $3 \mathrm{R}$ regenerator is to recover a data into original bit sequence. The modulated NRZ signal, data bit sequence and recover of input signal are three outputs is produced by a $3 R$ regenerator. The BER analyzer is straight associated to the output of $3 \mathrm{R}$ regenerator for avoid the additional connection between transmitter and receiver.

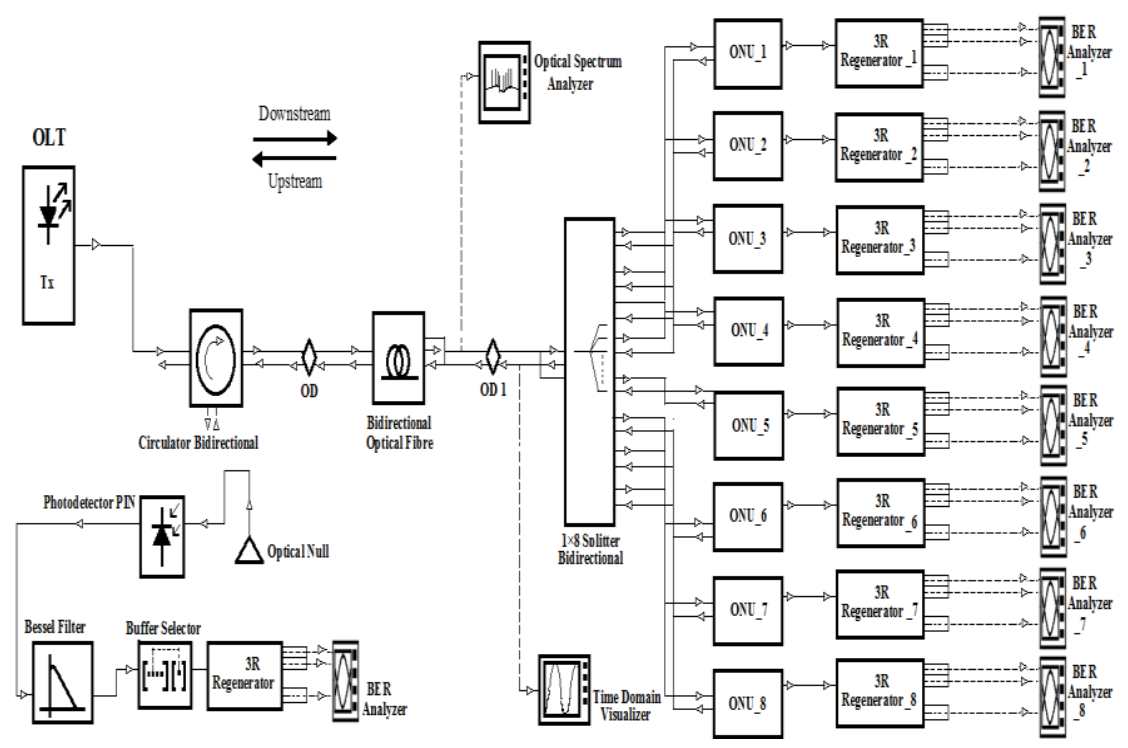

Fig.2 Simulation design of bidirectional BPON

In upstream transmission, signal is transmitted from ONU to PIN photo detector is located at OLT is convert a light source into electrical source. A Bessel filter is allied to photo detector used to cut the high Bessel frequencies and reduces the peak overshoot. The performance of uplink is analyzed by a BER analyzer is coupled to $3 \mathrm{R}$ regenerator.

\section{RESULTS AND ANALYSIS}

The performance of deployed bidirectional BPON system is evaluated according to less insertion losses at circulator/splitter and low attenuation in optical fiber in downstream direction at $1550 \mathrm{~nm}$ wavelength. When the signal is sends from transmitter to receiver, there in ODN signal quality is degraded due to attenuation and noise in optical fiber. Additionally, some other effects i.e. non-linear impairments and insertion losses occurred in circulator and splitter during the transmission of optical signal. We visualized the variations of parameters are eye height, minimum bit error rate and quality factor in two cases i.e. minimum insertion losses at circulator and splitter and low attenuation in optical fiber. Firstly, we analyzed the BPON system performance with low insertion losses is $0.2 \mathrm{~dB}, 0.6 \mathrm{~dB}$, $1 \mathrm{~dB}$ and $1.4 \mathrm{~dB}$ at circulator respectively. Figure 3(a), 3(b), 3(c) and 3(d) shows eye illustration of bidirectional BPON system at ONU and observed a high quality factor and minimum bit error rate with low insertion losses. If losses increases quality factor decreases is shown in simulation results.

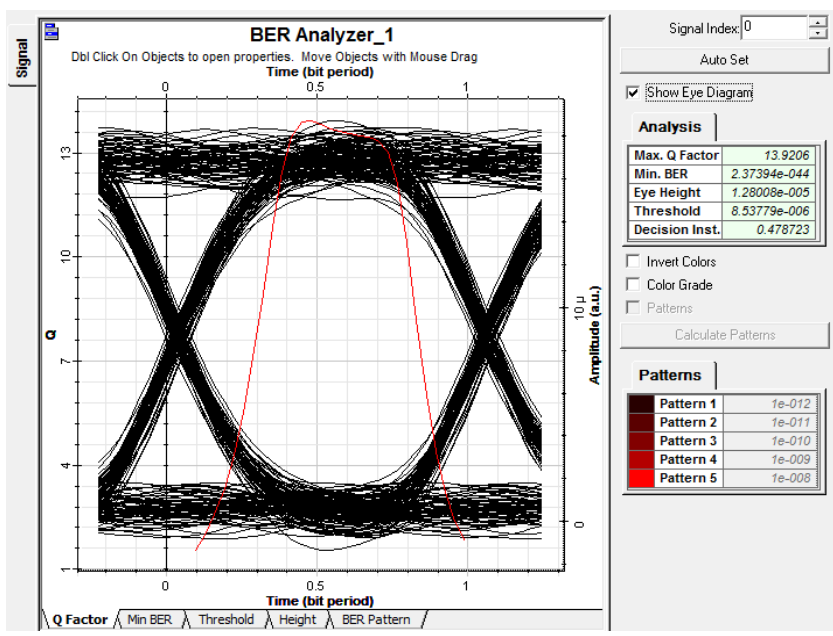

Fig. 3 (a) eye diagram of insertion losses is $0.2 \mathrm{~dB}$ at circulator 


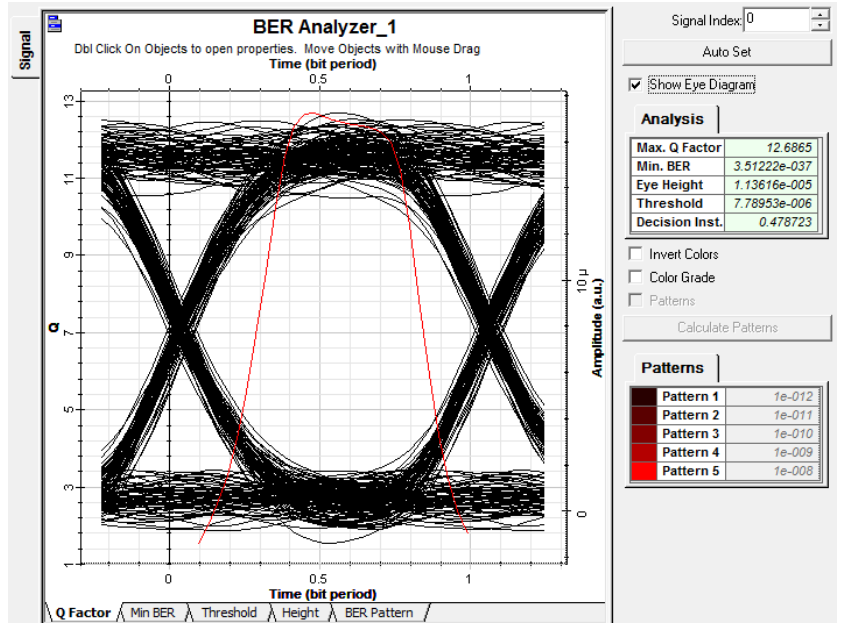

Fig. 3 (b) eye diagram of insertion losses is $0.6 \mathrm{~dB}$ at circulator

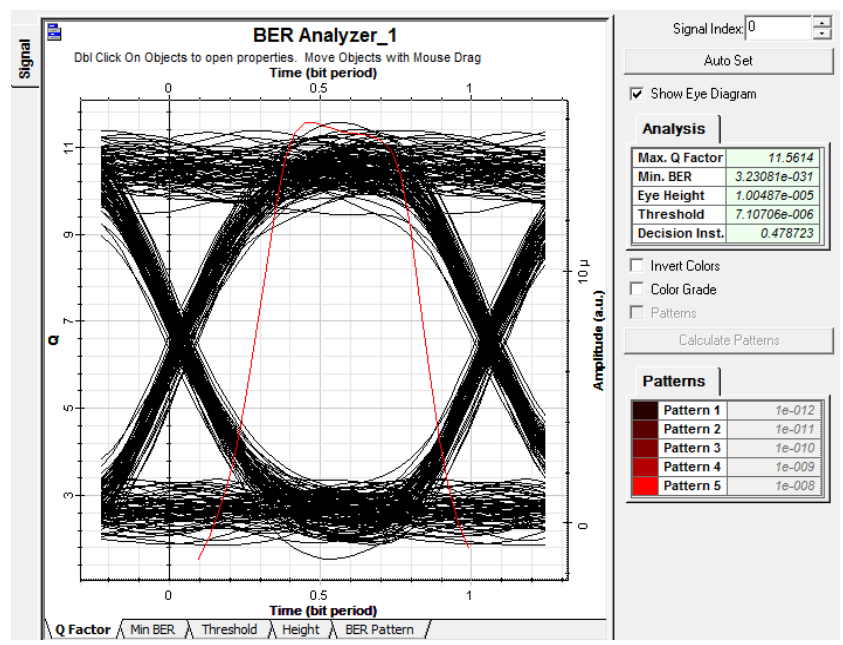

Fig. 3 (c) eye diagram of insertion losses is $1 \mathrm{~dB}$ at circulator
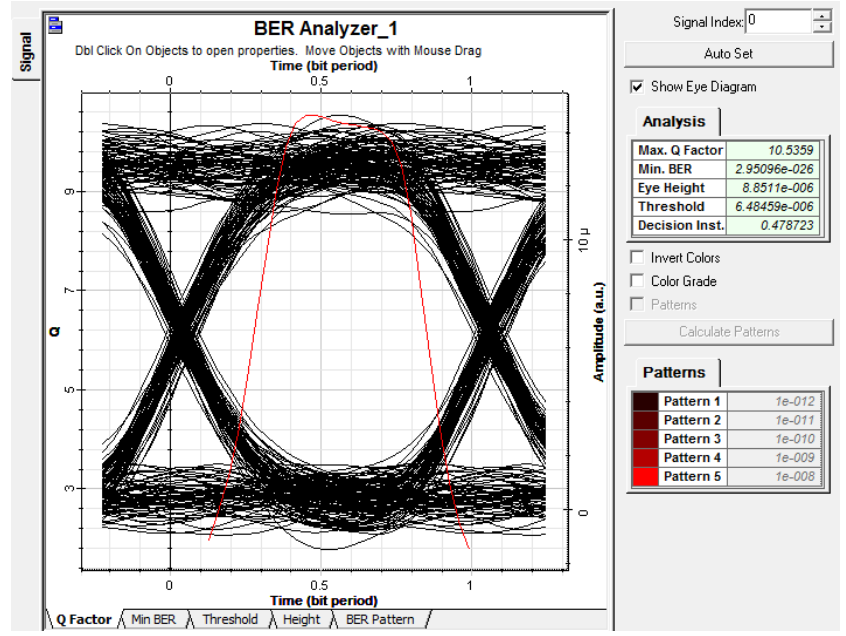

Fig. 3 (a) eye diagram of insertion losses is $1.4 \mathrm{~dB}$ at circulator

Also, a insertion losses is taken at splitter is $0.2 \mathrm{~dB}, 0.6 \mathrm{~dB}$, $1 \mathrm{~dB}$ and $1.4 \mathrm{~dB}$ respectively. It is shown in eye illustration of BPON network at ONU in figure 4(a), 4(b), 4(c) and 4(d).

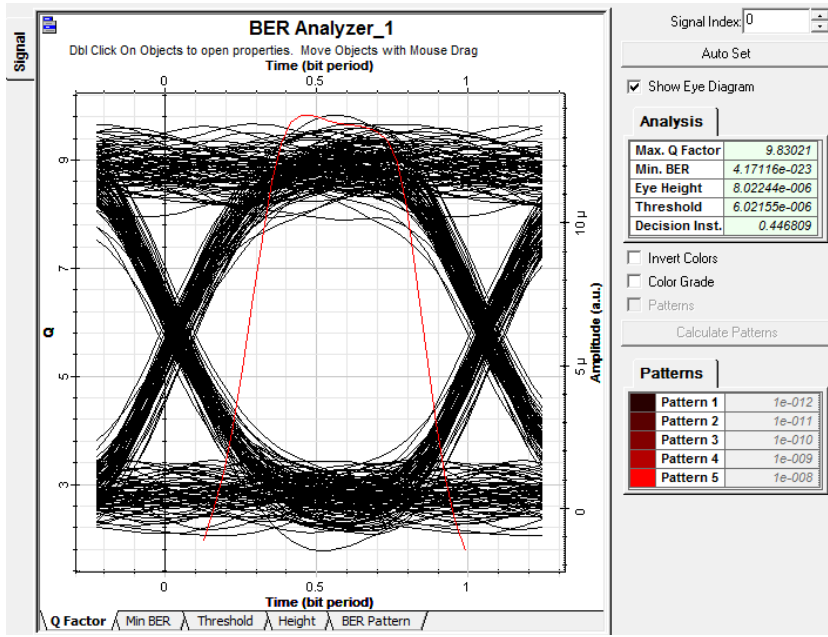

Fig.4 (a) eye diagram of insertion losses is $0.2 \mathrm{~dB}$ at splitter

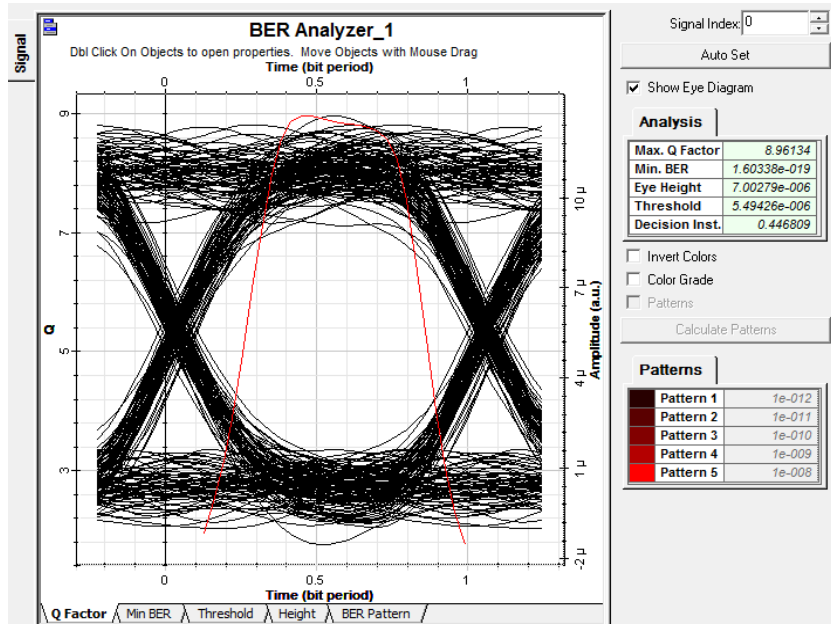

Fig. 4 (b) eye diagram of insertion losses is $0.6 \mathrm{~dB}$ at splitter

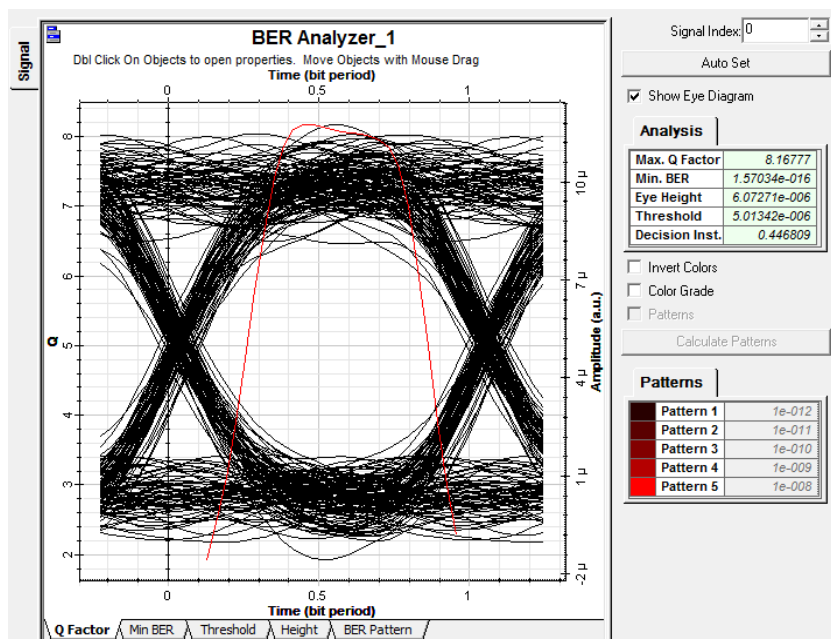

Fig. 4 (c) eye diagram of insertion losses is $1 \mathrm{~dB}$ at splitter 


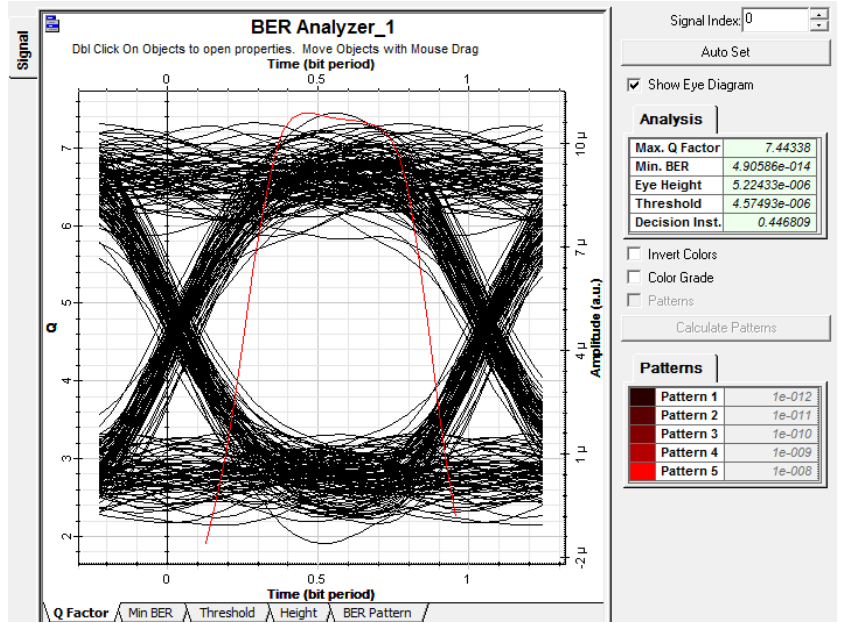

Fig. 4 (c) eye diagram of insertion losses is $1.4 \mathrm{~dB}$ at splitter

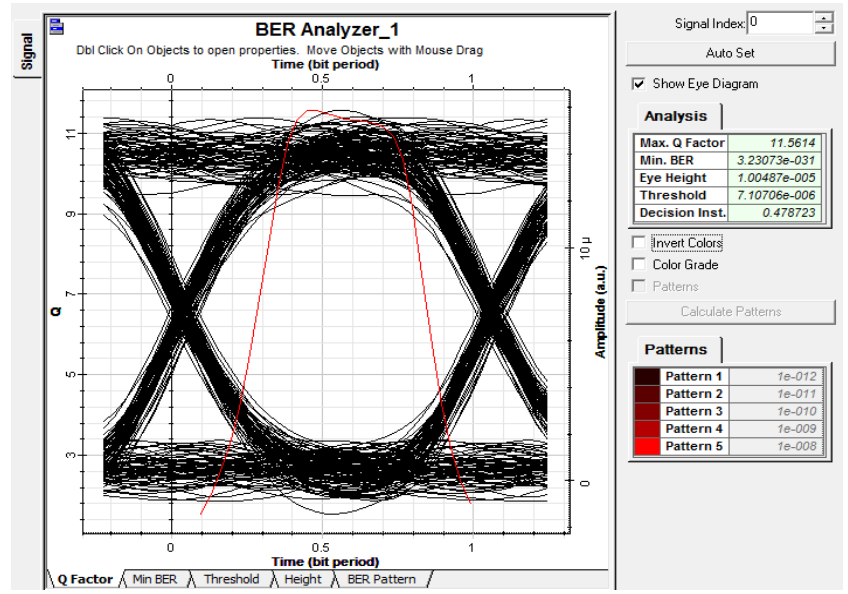

Fig.5 eye diagram of optical fiber attenuation at $0.1 \mathrm{~dB} / \mathrm{km}$

For sending a signal from OLT to ONU, a NRZ modulation format is used and it gives a better performance of BPON system than RZ because RZ format having a small pulse width and suffer from more dispersion and attenuation effects. NRZ format is also suitable for long distance transmission and it require a less bandwidth so it less affected by insertion losses and attenuation. The downstream signal operated at $1550 \mathrm{~nm}$ wavelength and attenuation in optical fiber at $0.1 \mathrm{~dB} / \mathrm{km}$ quality factor of signal is 11.5614 and minimum bit error rate is $3.23073 \mathrm{e}-031$ achieved.

While the system performance depends on large eye opening, minimum bit error rate and maximum quality factor. The maximum quality factor is directly proportional to minimum BER means if bit error rate increases signal quality degraded and noise is present in the signal. A maximum quality factor is achieved having a less losses in the system and vertical eye opening is also large is indicates BPON system has a greater immunity to losses and crosstalk in the signal.

\section{CONCLUSION}

In this work, achieve a better performance of bidirectional BPON system in downstream direction at ONU using a 7.0 optisystem simulator by using a signal in NRZ modulation format which has low insertion losses i.e. $0.2 \mathrm{~dB}, 0.6 \mathrm{~dB}, 1 \mathrm{~dB}$ and $1.4 \mathrm{~dB}$ at circulator and splitter. Additionally, attenuation in optical fiber is $0.1 \mathrm{~dB} / \mathrm{km}$ gives better quality factor is
11.5614 and minimum bit error rate is 3.23073e-031.It can be analyzed that higher losses degrade the quality of service and increases the error bit rate. The insertion losses can also be decreased by using a TSOA and EDFA amplifiers by raising a power level but it will increase the network cost.

\section{ACKNOWLEDGEMENTS}

I want thanks to my guide Mr. Atul Mahajan Associate Professor in Amritsar College of Engineering and Technology, Amritsar, for providing a help and guidance.

\section{REFERENCES}

[1] Yasser Almalaq and Mohammad A. Matin, “ Performance Analysis of Bidirectional Broadband Passive Optical Network Using Erbium Doped Fiber Amplifier," IOSR Journal of Engineering, Vol. 04, Issue 02, Feb. 2014.

[2] Varsha Lohani and R.S.Prasad, "Design and Simulation of Hybrid WDM/TDM Passive Optical Network," International Journal of Computer Applications, Volume 119, No.6, pp. 27-28, June 2015.

[3] Tao Hu, Juhao, Fang Ren, Ruizhi Tang, Jinyi Yu, Qi Mo, Yili Ke, Cheng Du, Zhijian Liu, Yongqi He, Zhengbin Li and Zhangyuan Chen, "Demonstration of Bidirectional PON Based on Mode Division Multiplexing," IEEE Photonics Technology Letters, Jan 2015.

[4] Elaine Wong, "Next-Generation Broadband Access Networks and Technologies," IEEE Journal of Light wave Technology, Vol.30, No. 4, pp. 597-606, Feb. 2012.

[5] Chinky rani, Kulwinder singh and Bhawna utreja, "Performance analysis of bi-directional broadband passive optical network using travelling wave semiconductor optical amplifier," International Journal of Engineering Research and Applications, Vol. 3, Issue 4, pp. 114-118, Jul-Aug 2013.

[6] Sumedha Kaushik and Ankur Singhal, "Mitigation of Crosstalk in Passive Optical Network," International Journal of Advanced Research in Computer Science and Software Engineering, Volume 2, Issue 5, pp. 317-320, May 2012.

[7] Soo-Jin Park, Chang-Hee Lee, OSA, Ki-Tae Jeong, Hyung-Jin Park, Jeong-Gyun Ahn, and Kil-Ho Song, "Fiber-to-the-Home Services Based on WavelengthDivision-Multiplexing Passive Optical Network," IEEE Journal of Light wave Technology, Vol. 22, No. 11, pp. 2582, November 2004.

[8] K. Iwatsuki, "Application and Technical Issues of WDM-PON," Proc. SPIE 7620, Broadband Access Communication Technologies IV, Vol. 7620, pp. 762900c1-762900c9, Jan 2010.

[9] Sumanpreet and Sanjeev Dewra, "A review on Gigabit Passive Optical Network," International Journal of Advanced Research in Computer and Communication Engineering, Vol. 3, Issue 3, pp. 5844-5848, March 2014.

[10] S.F. Shaukat, U. Ibrahim and Saba Nazir, "Monte Carlo Analysis of Broadband Passive Optical Networks," World Applied Sciences Journal, pp. 1156-1164, 2011. 